\title{
Assessing the power transfer performance of A Lattice Tower Overhead Line System
}

\author{
K. Kopsidas \\ The University of Manchester \\ School of Electrical and Electronic Engineering, \\ PO Box 88, Manchester, M60 1QD, UK. \\ konstantinos.kopsidas@manchester.ac.uk
}

Keywords: Aluminium alloy conductors (AAAC), aluminium conductor steel reinforced (ACSR), ampacity, high-temperature low-sag (HTLS), overhead line, re-conductoring, sag, span, thermal rating, uprating.

\begin{abstract}
This paper examines the overall performance of overhead power lines (OHL) considering their electro-mechanical properties, with a focus on lattice tower structures. Performance analysis of commonly used aluminium alloy conductors (AAAC) on a $275 \mathrm{kv}$ lattice tower system and the subsequent comparison with the corresponding performance of the conductors on a $33 \mathrm{kV}$ wood pole structure highlights the effect of the OHL structure strength on the overall system performance. Further results from the analysis of the lattice tower structure help to evaluate the effect of span length, conductor weight and bundle configuration on the OHL system performance. Finally, a holistic analysis illustrating the benefits of the use of novel conductors on lattice tower structures at "normal" operating temperatures to avoid increased losses is reported and discussed.
\end{abstract}




\section{Introduction}

Environmental and economic barriers to building new lines, in addition to increased electrical power demand, have led to significant strides to identify ways to increase the capacity of existing Overhead Power Lines (OHL). This is usually achieved by increasing either the thermal or the dynamic limit of an OHL system. The latter involves the use of equipment which decreases the line impedance, achieving consequently phase current optimization and voltage drop reduction [1-5]. The focus of this paper, however, is on the former aiming to identify the system's electro-mechanical constraints and propose methods to improve the thermal limits of an existing OHL system that require small structure modifications, thereby minimizing the cost of structure reinforcement and the rights-of-way permission requirements.

Centrally linked to this topic of thermal uprating is re-conductoring, which involves the replacement of existing conductors with conductors of larger sizes or alternative materials and technologies. In this way the conductor resistance and/or sag are reduced, increasing the system's power transfer capacity. High-Temperature Low-Sag (HTLS) conductors have opened the horizons for different conductor designs, employing new composite materials and technologies, which allow further increase in a conductor's thermal rating without losing their mechanical strength $[6,7]$. When investigating the performance of these newly developed conductors it is also important to consider their weight under all conditions expected to be experienced by the OHL. The weight affects the system's mechanical stress and, in some cases, is the limiting factor of the maximum conductor diameter. Increasing the diametrical size of the conductor, to obtain higher ampacities, 
may result in the need to reinforce the OHL structures increasing, therefore, the upgrading costs that may have being avoided by operating a smaller conductor at a higher temperature. Therefore, it is crucial to consider conductor and weather loading (conductor resultant weight) along with OHL structure properties in the evaluation of thermal rating, rather than solely compare conductor properties in order to identify optimum designs and conductor sizes for a given system [6, 8-11].

Another relevant issue when evaluating lattice OHLs is the bundle configuration employed. Early work on performance of bundle configuration identified the advantages of bundle conductor configuration underlined their key role on, primarily, conductor electrical stresses (e.g. radio interference, corona losses) and, secondarily, on the mechanical characteristics $[12,13]$. Furthermore, analysis of reactive supply requirements is also considered as an important parameter for the selection of bundle configuration [13]. Consequently, conductor bundle configuration has been used as a technique to increase mainly the OHL's surge impedance loading and reduce the maximum mechanical loading on a lattice tower OHL, but not for the way the bundle affects the electrical loading of the system.

In earlier work on a case study of a $33 \mathrm{kV}$ wood pole structure [14] we showed the importance of the OHL structure on the conductor's sag performance which can be classified into three zones:

- Weak conductor zone: The low conductor strength is the main reason for excessive sag. 
- Everyday Tension (EDT) zone: The sag performance of the conductor on the system is driven by the conductor's self-damping vibration limit.

- Weak OHL zone: Further increase in conductor size results only in an increase of conductor weight as maximum conductor tension (MCT) is limited by the OHL structure.

These zones define the conductor's sag performance, which is the main factor that limits the ground clearance and consequently the conductor's ampacity [14].

This paper extends the analysis and results of [14] to lattice tower systems and highlights the effects of structure properties on OHL design principles by comparing two different standard OHL structures. Furthermore, it explains how the sag zones [14, 15] are affected by the OHL structure strength and the conductor bundle configuration and consequently how these zones are manifested on different OHLs. The analyses involve the effect of span length, conductor weight and bundle configuration on the sag-ampacity performance. The potential benefits that can be gained from the use of novel conductors on lattice tower structures, particularly at "non-elevated" operating temperatures, are also discussed.

\section{Methodology}

In order to evaluate different uprating methods and their potential benefits for an OHL system, a holistic computational methodology detailed in $[15,16]$ and briefly summarised here, is used. This methodology facilitates sag, ampacity and tension calculations while considering the electro-mechanical properties of the system. As a result, it enables the 
selection of the most suitable conductor for a given system and consequently helps to identify the best option of conductor size and technology type.

Conductor sag and ground clearance depend on the OHL system structure, the electrical and mechanical conductor properties, the environment and operating conditions $[15,17$, 18]. The critical operating loading conditions are those that result in the maximum sag. Therefore, both maximum mechanical and maximum electrical loading conditions have to be investigated, one of which influences the designed minimum ground clearance and consequently, the power rating of a particular system.

The maximum mechanical loading (i.e. weather loading) of the OHL system influences the maximum conductor sag developed during the harsh weather conditions when the conductor is not electrically loaded. The maximum electrical loading of the OHL is influenced by the maximum mechanical loading of the line, the maximum operating temperature, the ambient temperature and the properties of the conductor. These loading conditions determine the conductor sag, tension and ampacity at maximum operating conductor temperature $\left(\mathrm{T}_{\mathrm{MAX}}\right)$ and are limited by the minimum permitted clearance to the ground $[18,19]$ and/or the temperature at which the conductor suffers irreversible loss of strength [20].

A holistic perspective on system performance is taken within this methodology by considering the four groups of data (OHL, weather, conductor and operational) into the calculations. Computations are performed at three distinct levels, defined by the 
mechanical, electrical and ageing properties of the system, which interlink to compute the final system conditions and its rating.

The conductor sag at maximum operating temperature has to be evaluated based on the MCT which is initially calculated within the mechanical computation section. MCT is influenced by the structure, conductor and vibration limitations, however, it is not affected by the operating conditions and consequently it is used as the baseline to compute the tension and sag at any operating temperature (or for a given $\mathrm{T}_{\text {MAX }}$ ). The electrical computations are then performed to determine the ac resistance of the conductor at the specific operating temperature. At the end, the ageing computation, determines the conductor plastic elongation (creep-strain) caused by the long-term ageing at system's designed everyday temperature, the short-term ageing at elevated operating temperatures, and the MCT ageing caused by the maximum tensile load and its applied duration. The plastic elongation is then converted into the equivalent thermal elongation, and the final system conditions of a particular system (conductor and OHL structure) are determined. These are the conductor ampacity, conductor sag with creep, conductor sag when creep is negated as well as the initial over-tension required to negate the calculated ageing effect.

\section{System Description}

According to this methodological framework [16], it is important to specify the variables that define the OHL structure and the weather loading in order to initiate the 
computations at the critical loading conditions (i.e. $\mathrm{MCT}$ and $\mathrm{T}_{\mathrm{MAX}}$ ) as well as the initial conductor treatment for creep mitigation.

\subsection{The 275 kV Lattice Tower System}

The $275 \mathrm{kV}$ lattice tower studied here is a typical L3 type standard tower. The L3 tower has a maximum loading tension of $72 \mathrm{kN}$ including the safety factors [21] while its ultimate tension strength is $180 \mathrm{kN}$ and its weight $76.17 \mathrm{kN}$. The wood pole structure, used for the comparative analysis, is a typical $33 \mathrm{kV}$ single (stout) wood pole distribution line with a $23.3 \mathrm{kN}$ maximum loading tension including the safety factors [14, 22, 23]. Both OHL structures are shown in Fig. 1.

Figure 1

\subsection{Conductor Types Studied}

The performance of five different conductor types on the above system is investigated in this study. These types and their properties which are derived from ASTM [24-26] and [6, $7,11,27]$ are described in Table 1 . The first two types are commonly used conductors with the ACSRs considered in two groups, the 'soft' having lower steel-to-aluminium ratio than the 'hard' ones. This distinction is the result of the steel content influence on conductor rated breaking strength (RBS), resistance, and weight which make similar cross-sectional conductors to have different overall performance on the system. The ACCR and ACCC/TW are novel composite conductors with HTLS performance $[6,7]$.

Table 1 


\subsection{Initial Conditions for Calculations}

The weather conditions where the OHL structure is installed are also part of the system specification and define the weather loading (i.e. MCT). The case of "normal" altitude loading is considered here, with a $380 \mathrm{~N} / \mathrm{m}^{2}$ wind pressure and $12.5 \mathrm{~mm}$ radial ice thickness with $913 \mathrm{~kg} / \mathrm{m}^{3}$ density at $-5.6^{\circ} \mathrm{C}[23,28]$. Furthermore, the EDT, 20\% RBS for aluminium based conductors, is applied at $5{ }^{\circ} \mathrm{C}$. The maximum electrical loading conditions from [29] are used with conductor $\mathrm{T}_{\mathrm{MAX}}$ varying form $70{ }^{\circ} \mathrm{C}$ to $100{ }^{\circ} \mathrm{C}$, depending on the investigation and conductor technology, for the steady state thermal rating computations.

For the modelling of the aging computations, the weather conditions of the OHL systems for the estimated period in service need to be defined (by prediction). These include the maximum weather and electrical loading, the designed conductor EDT at everyday temperature, as well as their predicted duration. For the purpose of this analysis the EDT conditions are considered for $98 \%$ of a 10 year period, while maximum operating temperature (usually set at $70{ }^{\circ} \mathrm{C}$ ) and maximum weather loading (set at $-5.6{ }^{\circ} \mathrm{C}$ ) each occur $1 \%$ of the time. When $\mathrm{T}_{\mathrm{MAX}}$ 's are set above $75^{\circ} \mathrm{C}$, the elevated temperature creep effect is also calculated [30-33].

\section{Performance Analysis Considering OHL System Properties}


The effect of different design properties (OHL structure strength, span length, and conductor bundle configuration) on OHL system performance is investigated in this section.

\subsection{Structure Strength Effect}

The effect of the OHL structure strength is studied through the comparison of two standard systems: the weaker $33 \mathrm{kV}$ OHL system and the stronger $275 \mathrm{kV}$ lattice tower OHL system which is of central interest in this paper (Fig. 1). Comparisons at this stage are performed using AAAC conductors because they are more uniform and thus allow for the structure strength effect on system performance to be observed. For the same reason, the span length of the L3 system is set to $110 \mathrm{~m}$ and the radial thickness of ice to $9.5 \mathrm{~mm}$. Finally, for simplicity the conductor ageing (creep) is not included in these calculations as the focus is on the effect of structure strength on the sag zones.

Table 2 presents the calculated sag and tension values for the standard AAACs studied at both critical loading conditions as well as their ampacity at $70{ }^{\circ} \mathrm{C}$. Regarding the performance of the lattice tower system, it can be observed that the MCT of the two smallest conductors is limited by their strength (50\% RBS), while the MCT for the largest one is limited by the OHL strength. The MCT for all other conductors is controlled by their self-damping vibration limit tension [15]. When the calculated values (of sag and ampacity) are compared with the corresponding values for the wood pole system it can be seen that the stronger lattice structure can withstand larger conductors without reducing their sagging performance. However, the smaller conductors have the same sag-ampacity performance on both structures. 
Table 2

Fig. 2 illustrates the sag performance of the different AAACs (of Table 2) at maximum weather $\left(-5.6{ }^{\circ} \mathrm{C}\right)$ as well as at maximum electrical $\left(70{ }^{\circ} \mathrm{C}\right)$ loading conditions for the wood pole and lattice tower structures. It can be observed that the conductors of the weak conductor zone develop excessive sag at extreme weather loading $\left(-5.6{ }^{\circ} \mathrm{C}\right)$ and therefore, the weather loading is the critical design condition for these systems. This is mainly due to the reduced conductor strength that the small AAACs provide.

Figure 2

The results of this analysis show that as the size of the conductor installed on these structures increases, the EDT zone is developed (Fig. 3). Within this zone the OHL system's performance is determined by the maximum electrical loading conditions. It can also be observed that the increased strength of conductors is utilized by the OHL structure since the critical weather loading sag ( $\mathrm{sag}$ at $-5.6{ }^{\circ} \mathrm{C}$ ) is further reduced. The right boundary of the EDT zone is defined by the strength of the structure and, as shown in Fig. 2, the weaker wood pole structure has smaller EDT zone while the stronger lattice tower structure has an extensive EDT zone allowing larger and heavier conductor sizes to be installed improving the electrical performance of the OHL system. The opposite occurs with the weak OHL zone which shrinks, whereas, the weak conductor zone is not affected by the structure as it is only influenced by the conductor strength. When the maximum conductor size that can be installed in the wood pole structure exceed the size of Upas 
(24.7 $\mathrm{mm}$ ), the strength of the cross-members and insulator pins may be affected by the vertical forces applied on the structure and therefore, additional reinforcing may be needed.

It is important to emphasize at this point, that the combined electrical and mechanical performance of the OHL systems studied in this section, could have been improved by manufacturing the conductors within the EDT zone (i.e. with diameters between $15 \mathrm{~mm}$ to $20 \mathrm{~mm}$ for the wood pole and up to $37 \mathrm{~mm}$ for the lattice tower) with weaker but more conductive aluminium alloy. In other words, using AL7 alloy would be a better choice than using the standard AL2 or AL5 [27].

A further increase of conductor size installed on the OHL structures worsens the sag performance (Fig. 2). When ground clearance constraints exist the maximum operating temperature of the OHL system will be reduced, constraining its electrical performance. This reduced sag performance of the larger conductors within the weak OHL zone is the effect of limited strength of the OHL structure and increased ice and conductor weight. Two effects are observed on the sag performance of the conductors within the weak OHL zone: (a) the increased sag developed at both critical conditions and (b) the different rates of change of the sag values between the weak (wood pole) and strong (lattice tower) OHL structures. These two effects indicate that light-weight conductor technologies can improve the performance of the (studied) OHL systems. The use of lighter materials will extend the EDT zone of the system to larger conductors and, therefore, enhance both the electrical and mechanical performance of the OHL system as a whole. Conversely, 
reinforcing the structure could have the same effect as installing lighter conductor technologies. It should also be noted that the strength of the conductors falling within the weak OHL zone is the least critical factor to be considered for the OHL system design.

The end of the EDT zone occurs when the critical weather loading performance curve of the OHL-conductor system reaches the minimum point (Fig. 2). At this point the standard Poplar $(20.1 \mathrm{~mm})$ and Araucaria $(37.3 \mathrm{~mm})$ conductors, among the ones examined here, perform best for the studied wood pole and lattice tower systems, respectively. Thus, this minimum point can be used to identify the most optimum conductor size on any given combination of OHL structure and conductor technology.

\subsection{Span Length Effect}

Lattice tower OHLs cover longer distances, and therefore, terrain constraints influence the span lengths. Different span lengths, covering variations within the most common range are modelled in order to identify the effect of this parameter on the mechanical and electrical system performance, as shown in Fig. 3. It should be noted that the maximum electrical loading conditions are the same as in the previous section (Structure Strength Effect) and thus the maximum electrical loading at $70{ }^{\circ} \mathrm{C}$, which is independent of span, is the same as in Table 2.

The sag performance of the lattice tower OHL system reduces with the increase of span length (Fig. 3). In the case of $440 \mathrm{~m}$ span length all the AAACs develop more than the $12 \mathrm{~m}$ maximum permitted sag by the $275 \mathrm{kV} \mathrm{L} 3$ structure exceeding the minimum safe 
clearance to the ground $[34,35]$. Therefore, the standard L3 tower cannot be used with $440 \mathrm{~m}$ span length. From Fig. 3 it can also be derived that the increase in span length shrinks the EDT zone and expands both the weak conductor and weak OHL zones. The increase in span, consequently, reduces the electrical performance of the system as the worse sag performance constrains either the maximum conductor size or $\mathrm{T}_{\mathrm{MAX}}$. In this case study, the sag of the large Araucaria $(37.3 \mathrm{~mm})$ and Redwood $(41 \mathrm{~mm})$ conductors increases with corresponding increase in the span length, and for span lengths larger than $330 \mathrm{~m}$, the Redwood conductor infringes the minimum clearance to ground at $70{ }^{\circ} \mathrm{C}$ operation. Consequently, lower operating temperature or smaller conductors have to be used in order to preserve the required clearances.

Figure 3

As already discussed earlier, the performance of the $440 \mathrm{~m}$ span length exceeds the permitted maximum sag even for the conductors within the EDT zone. This signifies the need for taller towers instead of stronger ones. In particular, for the examined system approximately $3 \mathrm{~m}$ extension legs are required to increase the permitted sag to $15 \mathrm{~m}$. This observation, consequently, leads to the conclusion that a smart tower design involves finding the optimal ratio of strength and height for the specified OHL system. An alternative option is to reduce the sag by changing conductor technology, which is investigated in Section 5. 


\subsection{Conductor Bundle Configuration Effect}

The twin bundle configuration is studied in this paper since this is the only one used for the L3 tower structure. The analysis does not involve the surge impedance loading and electrical stresses on conductor surface but only the effect on thermal loadings which have not been examined previously; that was mainly because initially the use of bundles was for voltage upgrading rather than for current uprating.

Fig. 4 compares the sag and electrical performances at $70{ }^{\circ} \mathrm{C}$ for the single and twin bundle configurations of the AAACs in Table 2, at different span lengths. The initial sag and the final sag with 10 years of conductor ageing are illustrated. The results in Fig. 4 show that the EDT zone is reduced when employing bundle configuration and it is vanished for the larger $330 \mathrm{~m}$ and $440 \mathrm{~m}$ spans. Among the conductors and span lengths studied here, the twin Poplar has the best sag performance while when increasing the size to twin Upas the sag increases considerably for span lengths of $330 \mathrm{~m}$ and above. By comparing the twin Poplar to single Araucaria as well as the twin Upas to single Redwood (Fig. 4) configurations, similar electrical and sag performances can be observed. Something not obvious from Fig. 4, however, is the difference in the total conductor weight the tower has to withstand when different bundle configurations are used. In particular, the aforementioned twin bundle configurations are approximately $40 \%$ lighter than the corresponding single ones and consequently stress the tower less on the vertical loading (Table 2). Therefore, the twin bundle configuration increases the efficiency of the system by reducing the weight the tower can hold allowing larger 
conductors (in twin bundle) for the same tower strength and consequently higher ampacities.

What is more important regarding the OHL system's thermal rating when bundles are employed and not mentioned in previous literature is the fact that the bundle configuration provides increased skin factor and reduced conductor stranding effects, in addition to increased heat dissipation through convection due to increased surface (compared to the single conductor of equivalent size). The reduced stranding effects resulted from the use of smaller conductors improve both the conductor's weight and its electrical resistance with corresponding benefits on the sag and ampacity of the OHL system.

Figure 4

The conductor ageing varies with the conductor size, bundle configuration, and span length (Fig. 4). The maximum ageing occurs when the OHL system is designed with single Poplar $(20.1 \mathrm{~mm})$ and up to single Sorbus $(33.39 \mathrm{~mm})$ conductors. Moreover, the twin bundle configuration reduces the ageing effect considerably for the conductors that are not within the weak conductor zone.

\section{Performance Comparison of Different Conductor Technologies}

The electrical and mechanical performance of the different conductor technologies are compared to evaluate benefits that may result from the improved properties (e.g. weight, 
linear expansion, strength) of novel conductor technologies, on the $275 \mathrm{kV}$ L3 system at normal operating temperatures (i.e. not above $100^{\circ} \mathrm{C}$ ).

\subsection{Singe Bundle Electro-mechanical Performance}

The L3 lattice structure described before (Fig. 1) is used with a single conductor configuration and span length of $330 \mathrm{~m}$, which is considered to approach an average OHL span configuration. The electrical and weather loading conditions detailed under the System Description section are used.

Figure 5

Fig. 5 (on the left) presents the sag with and without creep, and the ampacity performance of the various conductor types studied (Table I) at maximum electrical loading. The sag zones can again be distinguished for all the different technologies. The definition of the zone boundaries, however, is not as clear for the bi-material conductor technologies as it is for the AAACs due to their non-homogeneous composition, which leads to anomalies in their sag performance [36]. It can, additionally, be seen that the stronger and lighter the conductor technology the lower the sag values within the EDT zone; this also causes the EDT zone to expand to a wider range of larger conductor sizes. When the creep is considered in the calculations, the stronger conductors are less affected by the long term creep and therefore, have slightly improved their performance. The boundaries of the zones are not affected by the creep as it can be seen from the top and bottom graphs on the left hand side of Fig. 5. Furthermore, comparison of these two graphs highlights the importance of the inclusion of the ageing calculations in the analysis, since the ageing 
may indicate some conductors as inappropriate to install on a structure influencing the system's actual electrical performance. For example, the largest AAAC Redwood infringes the minimum clearance to ground after 10 years of operation by $50 \mathrm{~cm}$ (bottom Fig. 5), while, its initial sag performance was $5 \mathrm{~cm}$ below the maximum permitted sag (top Fig. 5).

The electrical performance comparison of the different conductors (right hand side of Fig. 5) at $70{ }^{\circ} \mathrm{C}$ is performed based on their diameter, weight and their resultant weight when maximum weather loading is considered. When the electrical performance of the conductors is compared based on their diameter (top right graph of Fig. 5) ACCC/TWs appear to be better than other designs due to their trapezoidal shaped strands and the resulting higher fill factor, while all other conductor types have very similar ampacities. However, the comparison of ampacities with respect to conductors' weight clearly indicates that the ACSRs are more resistive and this is particularly obvious for the hard ACSRs. For example, the Zebra $(28.6 \mathrm{~mm})$ conductor, which has similar weight as Rubus (31.5 mm) and 1033-T13 (31.7 mm), has much lower electrical performance (middle right graph of Fig. 5). In fact, this conductor has even worse performance than the lighter Drake-E $(28.1 \mathrm{~mm})$. In order to improve the system's electrical performance with soft ACSRs and achieve similar performance as with AAACs and HTLS conductors, Moose $(31.8 \mathrm{~mm})$ has to be installed over-stressing unnecessarily the structure by approximately $23 \%$ (Fig. 5). 
Furthermore, when the conductors' resultant weight is used to evaluate their electrical performance it can be derived that the Drake-E with the trapezoidal shape strands and the lighter core performs better than the other aluminium alloy conductors (ACCR, AAAC). Again, the ACSRs are the worst performing conductors as shown in Fig. 5 and their performance worsens when they are compared to the other conductor types at larger conductors. This indicates that performance comparison of novel HTLS with the ACSRs $[6,8-11]$ could be misleading. Instead, the AAACs which perform better compared to ACSRs at normal operating temperatures, should be considered in such comparisons even though there are structural differences (due to the bi-metallic properties of HTLS conductors).

The comparison of the conductor resistance based on cross area is not shown in the figure as the different conductor types have virtually identical performance. This may be the result of the designing principle of bi-material conductors to have similar volume resistivity with the AAACs.

\subsection{Twin Bundle Electro-Mechanical Performance}

The performance of the different conductors on the same structure is also compared when twin bundle configuration is considered. The electrical performance of these OHL systems can be calculated by doubling the ampacities in Fig. 5. The conductor sag performance changes considerably as shown in Fig. 6 where one can see that the EDT zone is not developed for the different conductor types studied here. 


\section{Figure 6}

The sag performance of the system with twin bundle configuration is heavily dependent on the conductor weight rather than its strength making the heavier conductors (hard ACSRs) to sag more than the lighter conductor types (e.g. AAACs) on the OHL structure. The novel ACCRs have similar performance to the AAACs at low temperatures while the ACCC/TWs, with similar weight to AAACs and lower thermal expansion coefficients, perform better than the other types at the same $\mathrm{T}_{\mathrm{MAX}}\left(70^{\circ} \mathrm{C}\right)$.

The larger conductors that can be installed in the structure without infringing the minimum ground clearance when the creep is considered are Poplar (20.1 mm AAAC), Panther (21 mm hard ACSR), 556-T16 (23.9 mm ACCR), and Grosbeak-E ( $25.1 \mathrm{~mm}$ ACCC/TW) with ampacities of 886.5 A, 908.3 A, 1110 A, and 1316 A, respectively. Therefore, from all these conductors Grosbeak-E has the best electrical performance is achieved by and is the conductor that can be installed on the OHL without infringing the required ground-clearance with the highest ampacity at $70{ }^{\circ} \mathrm{C}$. However, in order to make the comparison even more holistic, different maximum operating conditions should be considered up to the $\mathrm{T}_{\mathrm{MAX}}$ the conductor can operate without affecting considerably its ageing while preserving the required ground clearance on this specific system. 


\section{Operating Temperature Effect on System's Holistic Performance}

This section investigates the $275 \mathrm{kV}$ L3 OHL system at different operating temperatures ( $\mathrm{T}_{\mathrm{MAX}}$ 's) in order to identify the maximum power transfer capability of the system with each of the conductor technologies in twin bundle configuration and thus evaluate the overall system performance.

The electrical and mechanical performance of conductors of different types and sizes has been studied for the system at operating temperatures varying from $50{ }^{\circ} \mathrm{C}$ to $100{ }^{\circ} \mathrm{C}$. The aim is to identify the conductors that allow the maximum power transfer through the studied system without infringing the required $7 \mathrm{~m}$ ground clearance (i.e. $12 \mathrm{~m} \mathrm{sag}$ ), whilst keeping the losses at low levels. It should be noted here that even though the HTLS conductors can operate beyond $100{ }^{\circ} \mathrm{C}$ without any problem $[37,38]$ the AAAC and ACSR conductors are affected by the elevated temperatures above $75^{\circ} \mathrm{C}$ and their $\mathrm{T}_{\mathrm{MAX}}$ is limited to $90{ }^{\circ} \mathrm{C}$. Therefore, the duration of the operation at elevated temperatures (i.e. above $75^{\circ} \mathrm{C}$ ) was set to 72 hours for the 10 year period.

Fig. 7 illustrates the sag performance (top) of the different conductors and their corresponding ampacities (bottom) for the temperature constraints of $90{ }^{\circ} \mathrm{C}$ and $100{ }^{\circ} \mathrm{C}$. The soft ACSRs exceed the $12 \mathrm{~m}$ maximum sag and therefore are not presented in the figure as they are not suitable for this structure. It can also be seen that for the hard ACSRs two different maximum operating temperatures $\left(80{ }^{\circ} \mathrm{C}\right.$ and $\left.90{ }^{\circ} \mathrm{C}\right)$ are selected since a larger conductor can be employed with lower operating temperature. 
The graphs of Fig. 7 can be used to identify the ideal conductor size among different conductor types for this OHL system. The circles indicate the largest conductors that can be erected on the system with the best electrical performance and their ampacities at the corresponding operating temperatures.

The performance of the different twin bundle ACSR configuration with Panther and Lynx at $80{ }^{\circ} \mathrm{C}$ and $90{ }^{\circ} \mathrm{C}$ is very similar and both conductors perform worse when compared to Poplar (AAAC) at $90^{\circ} \mathrm{C}$. When the HTLS conductors are considered, the power transfer capacity of the line is increased by approximately 20\% (250 A) and 65\% (780 A) when the 477-T16 (ACCR) and the Grosbeak-E (ACCC/TW) are installed, respectively. It can also be observed that the ACCR and ACCC/TW conductors can operate even at higher temperatures than the $100{ }^{\circ} \mathrm{C}$ with the latter having an approximate $80 \mathrm{~cm}$ excess of sag allowance provided by the structure improving further the OHL's electrical performance.

Figure 7

The comparison of the $\mathrm{I}^{2} \mathrm{R}$ losses of these conductors at different operating temperatures, shown in Fig. 8, indicates that the Grosbeak-E (at $100{ }^{\circ} \mathrm{C}$ ) produces the least losses and the Lynx (at $90{ }^{\circ} \mathrm{C}$ ) the most with the HTLS conductors generating fewer losses than the AAACs at the same operating temperature. It is also important to note that Panther (ACSR) and Poplar (AAAC) have identical losses since the core magnetising factor for the examined range of temperatures for Panther is negligible. 
It is important to emphasize that the AAACs' sag performance depends on the duration of elevated temperature operation. For example, if instead of 72 hours at $90{ }^{\circ} \mathrm{C}$ operation, Poplar operates at $90{ }^{\circ} \mathrm{C}$ for about 240 hours, this would increase the conductor's sag by approximately $25 \mathrm{~cm}$ within the 10 year time.

Figure 8

\section{Discussion}

The effect of the structure's strength on the OHL system performance is investigated by a comparison between two different but well known OHL structures: the $33 \mathrm{kV}$ wood pole and the $275 \mathrm{kV} \mathrm{L3}$ lattice tower. This comparison helps to further understand the dependence of the sag zones [14] on the OHL structure strength and extend their application to the lattice tower systems. Furthermore, it illustrates the dynamic performance of the zones and their importance on identifying the optimal standard conductor size (minimum points if Fig. 2) to be erected on a given structure.

The increase in OHL structure strength extends the EDT sag zone to larger conductors and allows their installation on the system without reducing the minimum required ground clearance (Fig. 2) and, thus, improves the electrical performance of the system by allowing increased power transfer through the same corridor (Fig. 3). The same effect can be achieved by selecting conductor technologies of smaller core densities which results in lighter conductors. 
The effect of large spans cannot be reduced by installing stronger conductors or stronger towers (Fig. 4). Thus, the use of extension legs is more beneficial than the increase of the tower strength. This indicates the importance of optimizing the strength-to-height ratio of OHL structures. However, using lighter conductor technologies with lower thermal expansion coefficients could permit large span lengths (i.e. $440 \mathrm{~m}$ ) with shorter (or even without) tower extension legs and therefore, could reduce the structure cost demonstrating additional benefits that arise from novel conductor implementation at normal operating temperatures.

The use of a twin bundle configuration on the $275 \mathrm{kV}$ OHL has a twofold effect on improving the system's power transfer capability. Firstly, it increases the heat dissipation from the conductor to the ambient environment and secondly, it reduces the spiralling effect, which is more dominant on large conductors. The latter improves both the electrical and the mechanical performance of the system, as it reduces both resistance and weight of the conductor. Furthermore, the bundle configuration reduces the conductor weight by $40 \%$ indicating effective use of materials and cost efficiency since less aluminium is required for the conductors. All these benefits on thermal rating resulting from the use of bundles are not reported in previous literature.

The analysis of the performance of different conductor technologies on the lattice tower OHL system indicated that the AAACs have the best performance among the conventional technologies and these conductors should be included in performance 
evaluation of any novel HTLS technology instead of using only the ACSRs. A further improvement of the performance of AAACs can be achieved by employing alloys with lower resistivity and strength (e.g. AL7 or other alloys).

The ampacity of the studied conductor technologies is almost identical when the comparison is performed based on their cross-sectional area indicating that most probably the bi-material conductors are designed to have similar volume resistivity to AAACs, justifying that novel conductors are designed with electrical properties to match the existing ones and not to meet the needs of individual structures. However, when their electrical performance is compared based on their resultant weight (Fig. 5), the differences underline the importance of developing lightweight conductor technologies with increased fill factors (trapezoidal shape).

It is also critical to note that new conductor technologies allow larger conductor sizes to be employed on the same structure due to their reduced sag and therefore they may be used to reduce system copper losses when designed to operate at normal temperatures (e.g. $100{ }^{\circ} \mathrm{C}$ ). This alone may justify the additional cost of the conductor.

\section{Conclusions}

The analysis in this paper shows, firstly, the importance of the sag zones in identifying the optimal holistic (i.e. electro-mechanical) performance of conductors on arbitrary systems. Furthermore, it has been found that the weight of the conductor is one of the factors that 
constrain the system's performance in both structures and consequently the use of lighter (but weaker) materials could benefit the OHL system performance. This is also apparent from the performance comparison of the different conductor technologies on the lattice structure. The reduction of conductor weight (through the use of lighter material) leads to expansion of the EDT sag zone to larger conductors permitting increased thermal rating at normal operating temperatures. A similar effect can be achieved with the increase of the OHL structure strength, as shown with the comparison of the stronger lattice structure to the weaker wood pole one.

The analysis of different span lengths showed that the increase in structure strength cannot reduce the conductor sag of large span sections and therefore taller structures are required. New conductor technologies that provide low thermal expansion coefficient and lighter materials can also contribute to overcome this need.

On the $275 \mathrm{kV} \mathrm{L3} \mathrm{OHL} \mathrm{system} \mathrm{the} \mathrm{AAACs} \mathrm{appear} \mathrm{to} \mathrm{have} \mathrm{the} \mathrm{best} \mathrm{performance} \mathrm{among}$ the common technologies. Therefore, if interest is on the evaluation of the potential of reconductoring with novel conductors, comparisons should also be made with AAACs in order to have a more valid conclusion as opposed to the current practice $[6,8-11]$ to compare to only ACSRs because of their structure similarity.

Employing bundle configuration instead of larger conductors results in better electrical performance by the effective use of materials (i.e. $40 \%$ less aluminium). This improvement in performance is the result of the enhanced conductor cooling and more 
importantly the improved conductivity and reduced weight resulted from the lower spiralling effects of the smaller conductors used on bundle configurations.

Among the novel technologies investigated here it was also found that the ACCC/TWs appear to have better electrical performance on the studied OHL systems at the $70{ }^{\circ} \mathrm{C}$ operating temperature due to their low weight and thermal expansion coefficient. This supports the conclusion that HTLS conductors could also be beneficial at operating temperatures below $100{ }^{\circ} \mathrm{C}$, with reduced losses, and not only at elevated temperatures for which they are designed for (i.e. close to $180{ }^{\circ} \mathrm{C}$ ).

\section{Acknowledgement}

The author would like to cordially thank Prof. Simon M. Rowland for his contribution and support during the Supergen AMPerES project, of which this paper is part of.

\section{References}

[1] W. Seitlinger. (2001, 26 February 2007 ). Phase Shifting Transformers. Available: http://www.vatechetg.at/

[2] N. G. Hingorani, "FACTS-flexible AC transmission system," presented at the IEEE International Conference on AC and DC Power Transmission, Sep. 1991.

[3] P. H. Thiel, J. E. Harder, and G. E. Taylor, "Fuseless capacitor banks," IEEE Transactions on Power Delivery, vol. 7, pp. 1009-1015, 1992.

[4] M. Beanland, T. Speas, and J. Rostron, "Pre-insertion Resistors in High Voltage Capacitor Bank Switching," presented at the Western Protective Relay Conference, Oct. 2004.

[5] C. E. McCoy and B. L. Floryancic, "Characteristics and Measurement of Capacitor Switching at Medium Voltage Distribution Level," IEEE Transactions on Industry Applications, vol. 30, pp. 1480-1489, Dec. 1994.

[6] A. Alawar, E. J. Bosze, and S. R. Nutt, "A composite core conductor for low sag at high temperatures," IEEE Transactions on Power Delivery, vol. 20, pp. 2193-2199, 2005.

[7] 3M. (2006, Aluminium Conductor Composite Reinforced Technical Notebook (477 kcmil family) Conductor \& Accessory Testing. Available: 
http://www.energy.ca.gov/2004_policy_update/documents/2004-06-14workshop/public_comments/2004-06-28_3M_PART2.PDF

[8] H. W. Adams, "Steel Supported Aluminium Conductors (SSAC) for Overhead Transmission Lines," IEEE Transactions on Power Apparatus and Systems, vol. PAS-93, pp. 1700-1705, 1974.

[9] S. Kotaka, H. Itou, T. Matsuura, K. Yonezawa, and H. Morikawa, "Applications of Gap-type Small-Sag Conductors for Overhead Transmission Lines," SEI Technical Review, pp. 64-72, Jun. 2000.

[10] I. Zamora, A. J. Mazon, P. Eguia, R. Criado, C. Alonso, J. Iglesias, and J. R. Saenz, "High-temperature conductors: a solution in the uprating of overhead transmission lines," in IEEE Power Tech Proceedings, Porto-Portugal, 2001, pp. 1-6.

[11] F. R. Thrash, Jr., "ACSS/TW-An improved high temperature conductor for upgrading existing lines or new construction," in IEEE Power Engineering Society Summer Meeting, 2001, pp. 182-185.

[12] P. A. Abetti, C. B. Lindh, and H. O. Simmons, "Economics of Single and Bundle Conductors for Extra-High-Voltage Transmission," Transactions of the American Institute of Electrical Engineers, Part III: Power Apparatus and Systems, vol. 79, pp. 138-147, 1960.

[13] E. Hazan, "Extra-High-Voltage Single and Twin Bundle Conductors Electrical Characteristics and Conductor Selection," Transactions of the American Institute of Electrical Engineers, Part III: Power Apparatus and Systems vol. 78, pp. 1425$1432,1959$.

[14] K. Kopsidas and S. M. Rowland, "A Performance Analysis of Reconductoring an Overhead Line Structure," IEEE Transactions on Power Delivery, vol. 24, pp. 2248-2256, 2009.

[15] K. Kopsidas, "Modelling Thermal Rating of Arbitrary Overhead Line Systems," $\mathrm{PhD}$ Thesis, Electrical and Electronic Engineering, The University of Manchester, Manchester, UK, 2009.

[16] K. Kopsidas, S. M. Rowland, and B. Boumecid, "A Holistic Method for a Conductor's Ampacity and Sag Computation on an OHL Structure," IEEE Transactions on Power Delivery, in Print.

[17] R. Thrash, A. Murrah, M. Lancaster, and K. Nuckles, Eds., Overhead Conductor Manual. Southwire, 2007, p.^pp. Pages.

[18] "National Electrical Safety Code 2007 Edition," IEEE Std C2-2007, Aug. 2006.

[19] "BS EN 50423-3: Overhead electrical lines exceeding AC $1 \mathrm{kV}$ up to and including AC 45 kV - Part 3: Set of National Normative Aspects," British Standards, 2005.

[20] "IEEE Guide for Determining the Effects of High-Temperature Operation on Conductors, Connectors, and Accessories," IEEE Standard 1283-2004, pp. 1-28, 2005.

[21] "Overhead Line Handbook 'Linesmans Manual M1 for 132, 275, and 400kV overhead lines'," National Technical Training Centre (C.E.G.B.),Apr.1989.

[22] "BS 3288-2: Insulator and Conductor fittings for overhead power lines - Part 2: Specification for a range of fittings," British Standards, 1990. 
[23] "ENATS 43-40: Single Circuit Overhead Lines on Wood Poles for Use at High Voltage Up to and Including 33kV," Energy Networks Association Technical Specifications, Issue 2, 2004.

[24] "ASTM B 230/B 230M-99: Specification for Aluminium 1350-H19 Wire for Electrical Purposes," Annual Book of ASTM Standards, vol. 02.03, pp. 91-94, 2005.

[25] "ASTM B 231/B 231M-04: Specification for Concentric-Lay-Stranded Aluminium 1350 Conductors," Annual Book of ASTM Standards, vol. 02.03, pp. 95-105, 2005.

[26] "ASTM B 398/B 398M-02: Standard Specification for Aluminium -Alloy 6201-T81 Wire for Electrical Purposes," Annual Book of ASTM Standards, vol. 02.03, pp. 178-181, 2005.

[27] "BS EN 50183: Conductors for Overhead Lines - Aluminium-magnesium-silicon alloy wires," British Standards, 2000.

[28] "BS EN 50423-1: Overhead electrical lines exceeding AC $1 \mathrm{kV}$ up to and including AC $45 \mathrm{kV}$ - Part 1: General requirements - Common specifications," British Standards, 2005.

[29] "IEEE Standard for Calculating the Current-Temperature of Bare Overhead Conductors," IEEE Std. 738-2006 (Revision of IEEE Std 738-1993), pp. 1-59, 2007.

[30] "CIGRE SC22 - WG05: A practical method of conductor creep determination," Electra $N^{\circ} 24$, pp. 105-137, 1974.

[31] "CIGRE SC22 - WG05: Permanent elongation of conductors. Predictor equation and evaluation methods," Electra $N^{\circ} 75$, pp. 63-98, 1981.

[32] "CIGRE SC22 - WG12: The thermal behaviour of overhead conductors (Section 1 and 2)," Electra $N^{\circ}$ 144, pp. 107-125, 1992.

[33] "IEEE Guide for Determining the Effects of High-Temperature Operation on Conductors, Connectors, and Accessories," IEEE Std. 1283-2004, pp. 1-28, 2005.

[34] "BS EN 50341-1: Overhead electrical lines exceeding AC 45 kV - Part 1: General requirements - Common specifications," British Standards, 2001.

[35] "ENATS 43-8: Overhead Line Clearances," Energy Networks Association Technical Specifications, Issue 3, 2004.

[36] K. Kopsidas and S. M. Rowland, "Evaluating opportunities for increasing power capacity of existing overhead line systems," IET Generation, Transmission \& Distribution, vol. 5, pp. 1-10, 2011.

[37] 3M. (2003, Aluminium Conductor Composite Reinforced Technical Notebook (795 kcmil family) Conductor \& Accessory Testing. Available: http://multimedia.3m.com/mws/mediawebserver?mwsId=66666UuZjcFSLXTtN8Tt 4xfEEVuQEcuZgVs6EVs6E666666

[38] GeneralCables. (2008, Introducing The Next Generation Bare Overhead Conductor. Available: http://www.generalcable.com/NR/rdonlyres/6DEB849B-9EC6-43D180A1-719038AC9C4C/0/UTY0022R0406.pdf 


\section{List of Table \& Figures Captions}

Table 1: Basic properties of different conductor technologies.

Table 2: Conductor tension and sag at critical loading conditions for different AAAC (AL3) conductors at $110 \mathrm{~m}$ span length.

Figure 1: Outline diagram of the $275 \mathrm{kV} \mathrm{L3}$ type lattice tower (right) and $33 \mathrm{kV}$ single wood pole (left) structures.

Figure 2: Effect of structure strength on the sag zones and the electrical performance of AAACs.

Figure 3: Sag performance of AAACs on the L3 lattice tower structure for different span lengths.

Figure 4: Sag and ampacity of AAACs on the L3 lattice tower for different span lengths with and without creep mitigation at $\mathrm{T}_{\text {MAX. }}$.

Figure 5: Single conductor sag (left) and the ampacity performance (right) at $70{ }^{\circ} \mathrm{C}$ on $330 \mathrm{~m}$ span $275 \mathrm{kV}$ L3 tower OHL system.

Figure 6: Sag performance of twin bundle conductor configuration on the $275 \mathrm{kV} \mathrm{L3}$ OHL system with $330 \mathrm{~m}$ span length at $70{ }^{\circ} \mathrm{C}$ electrical loading.

Figure 7: Sag (top) and ampacity (bottom) performance of the $275 \mathrm{kV} \mathrm{L3} \mathrm{OHL} \mathrm{system}$ with $330 \mathrm{~m}$ span length with twin bundle conductor configuration.

Figure 8: Copper losses of the largest conductors permitted on the $330 \mathrm{~m}$ span $275 \mathrm{kV}$ L3 tower OHL system with twin bundle configuration at different operating temperatures. 


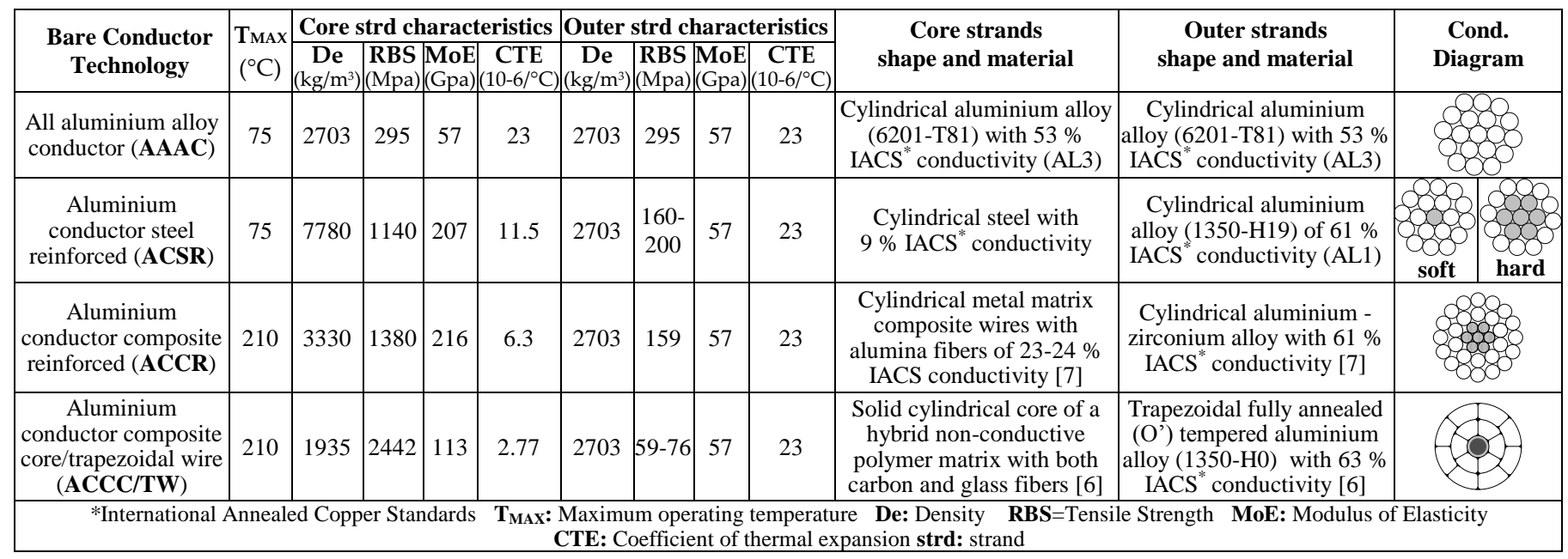

Table 1

\begin{tabular}{|c|c|c|c|c|c|c|c|c|c|c|c|c|c|}
\hline \multicolumn{4}{|c|}{ Conductor data } & \multicolumn{4}{|c|}{ Loading at $-5.6^{\circ} \mathrm{C}$} & \multicolumn{6}{|c|}{ Loading at $70^{\circ} \mathrm{C}$} \\
\hline \multirow{2}{*}{ Code Name } & \multirow{2}{*}{\begin{tabular}{|c|} 
Diameter \\
$(\mathbf{m m})$
\end{tabular}} & \multirow{2}{*}{$\begin{array}{c}\text { Area } \\
\left(\mathbf{m m}^{2}\right)\end{array}$} & \multirow{2}{*}{$\begin{array}{c}\text { GCW } \\
(\mathrm{kg} / \mathrm{m})\end{array}$} & \multicolumn{2}{|c|}{275 kV L3 } & \multicolumn{2}{|c|}{$33 \mathrm{kV}$ Wood } & \multicolumn{3}{|c|}{ L3 lattice tower } & \multicolumn{3}{|c|}{ Wood } \\
\hline & & & & MCT (kN) & Sag (m) & MCT (kN) & Sag (m) & CT $(\mathrm{kN})$ & \begin{tabular}{|l|} 
Sag (m) \\
\end{tabular} & $\mathbf{I}_{\text {MAX }}(\mathbf{A})$ & CT $(\mathrm{kN})$ & Sag (m) & $\mathbf{I}_{\text {MAX }}(\mathbf{A})$ \\
\hline ALMOND & 7.02 & 30.1 & 82.9 & 4.44 & 3.82 & \begin{tabular}{|l|}
4.44 \\
\end{tabular} & 3.82 & 0.36 & 3.45 & 123.2 & 0.356 & \begin{tabular}{|l|}
3.45 \\
\end{tabular} & 123.2 \\
\hline FIR & 8.85 & 47.8 & 131.8 & 7.055 & 2.63 & 7.055 & 2.63 & 0.89 & 2.21 & 164.1 & 0.887 & 2.21 & 164.1 \\
\hline HAZEL & 9.90 & 59.9 & 164.9 & 8.318 & 2.35 & 8.318 & 2.35 & 1.19 & 2.07 & 188.5 & 1.188 & 2.07 & 188.5 \\
\hline OAK & 14.00 & 118.9 & 327.4 & 13.09 & 1.82 & 13.09 & 1.82 & 2.36 & 2.08 & 288.4 & 2.359 & 2.08 & 288.4 \\
\hline MULBERRY & 15.90 & 150.9 & 423.1 & 15.363 & 1.69 & 15.363 & 1.69 & 3.08 & 2.06 & 333.8 & 3.085 & 2.06 & 333.8 \\
\hline ASH & 17.40 & 180.7 & 506.7 & 17.596 & 1.58 & 17.596 & 1.58 & 3.69 & 2.06 & 373.1 & 3.694 & 2.06 & 373.1 \\
\hline ELM & 18.80 & 211 & 591.5 & 19.853 & 1.49 & 19.853 & 1.49 & 4.31 & 2.06 & 410.4 & 4.310 & 2.06 & 410.4 \\
\hline POPLAR & 20.10 & 239.4 & 681.0 & 21.396 & 1.47 & 21.396 & 1.47 & 4.94 & 2.06 & 443.3 & 4.945 & 2.07 & 443.3 \\
\hline UPAS & 24.70 & 362.1 & 1030.2 & 30.92 & 1.24 & 23.333 & 1.65 & 7.48 & 2.06 & 571.4 & 5.907 & 2.63 & 571.4 \\
\hline YEW & 28.40 & 479 & 1362.9 & 39.4 & 1.14 & 23.333 & 1.92 & 9.89 & 2.06 & 677.7 & 6.826 & 3.02 & 677.7 \\
\hline TOTARA & 29.00 & 498.17 & 1417.1 & 40.8 & 1.12 & 23.333 & 1.96 & 10.28 & 2.06 & 694.2 & 6.975 & 3.08 & 694.2 \\
\hline RUBUS & 31.50 & 586.9 & 1686.3 & 47.05 & 1.08 & 23.333 & 2.17 & 12.27 & 2.06 & 765.6 & 7.749 & 3.30 & 765.6 \\
\hline SORBUS & 33.39 & 659.4 & 1894.7 & 52.27 & 1.04 & 23.333 & 2.34 & 13.8 & 2.06 & 821.3 & 8.300 & 3.47 & 821.3 \\
\hline ARAUCARIA & 37.30 & 821.1 & 2359.4 & 63.90 & 0.98 & 23.333 & 2.70 & 17.17 & 2.06 & 936.3 & 9.436 & 3.81 & 936.3 \\
\hline REDWOOD & 41.00 & 996.2 & 2862.4 & 72.00 & 1.00 & 23.333 & 3.08 & 19.9 & 2.16 & 1048.6 & 10.525 & 4.16 & 1048.6 \\
\hline
\end{tabular}

Table 2 


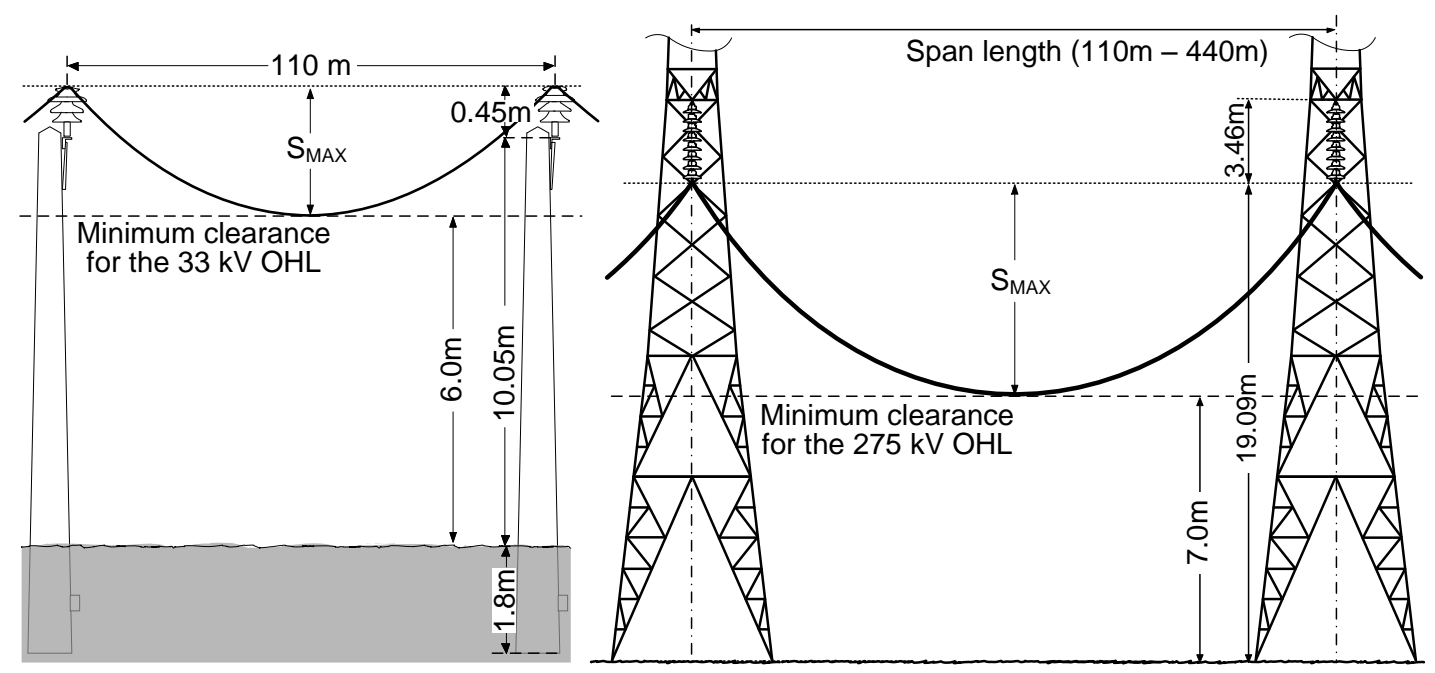

Figure 1

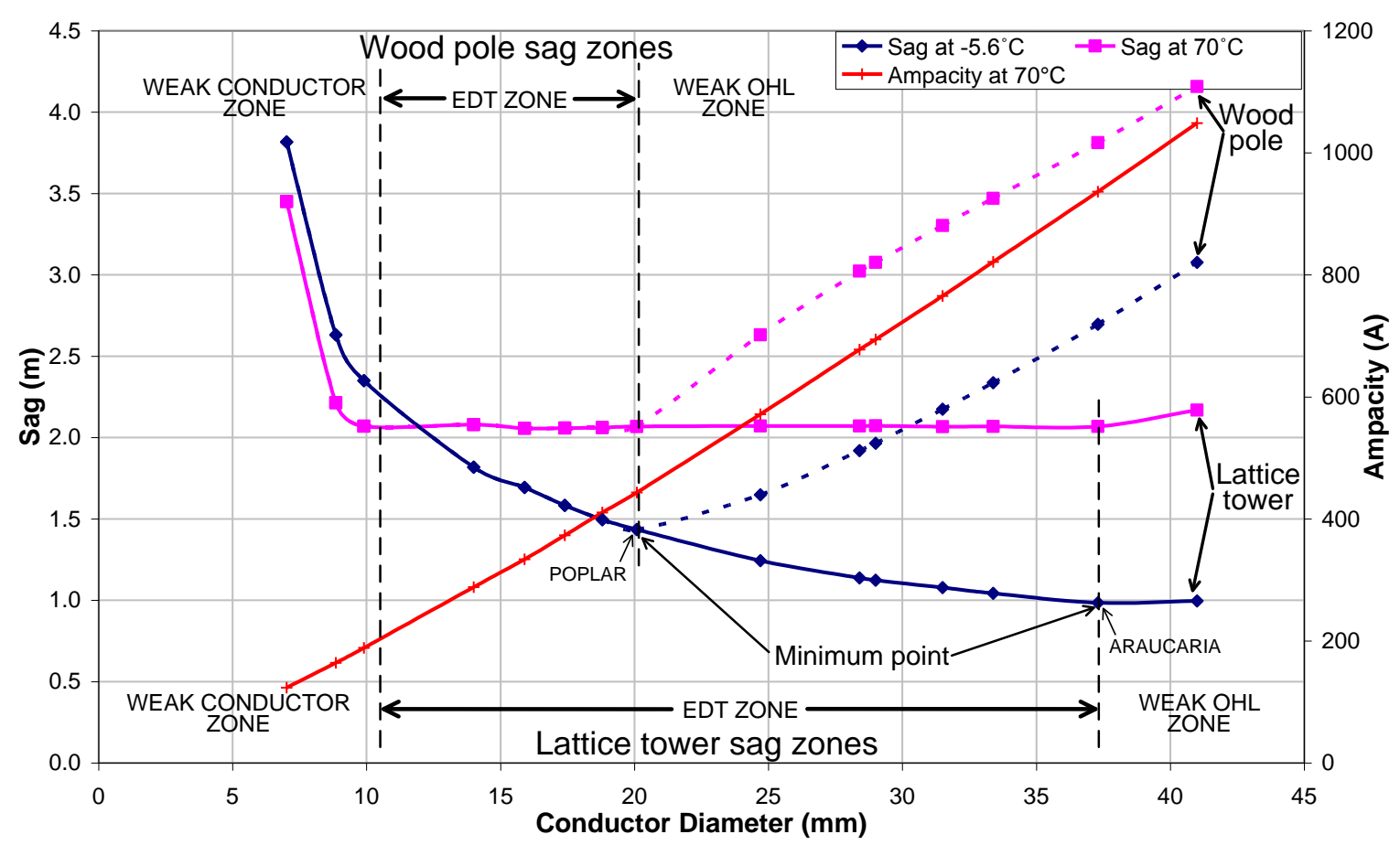

Figure 2 


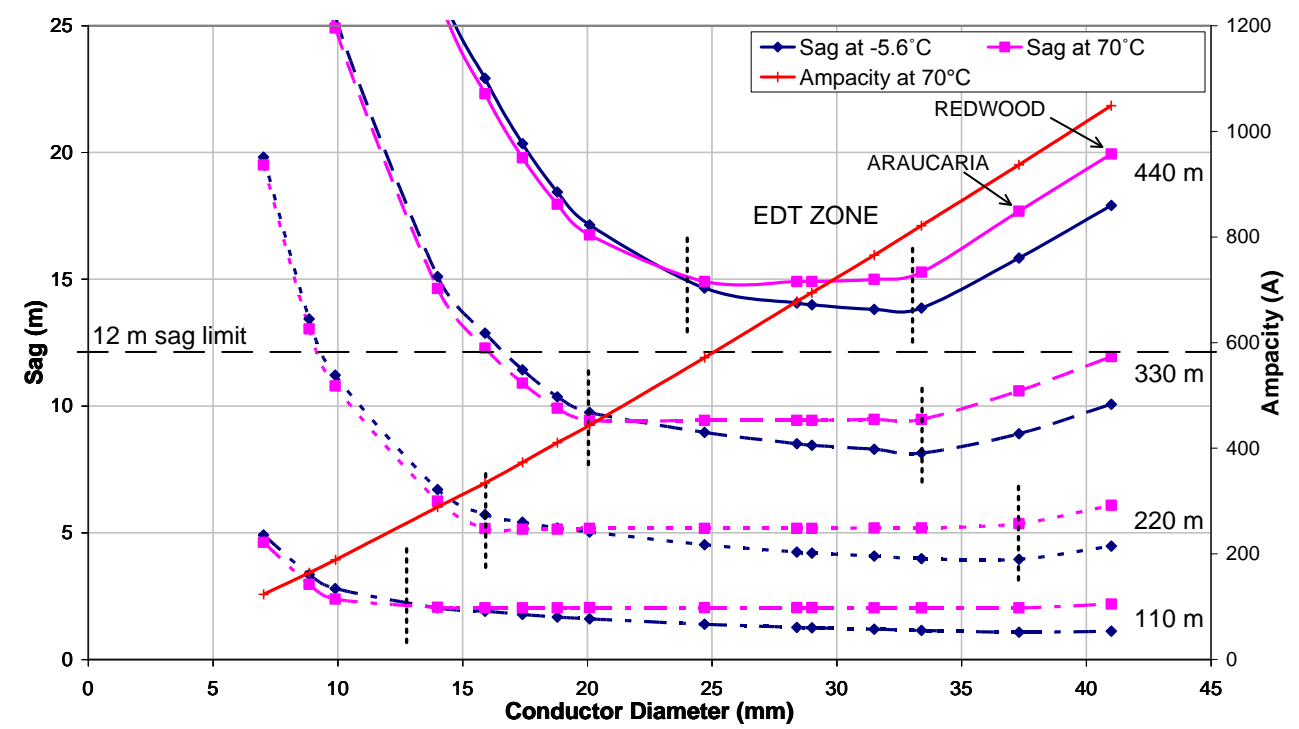

Figure 3

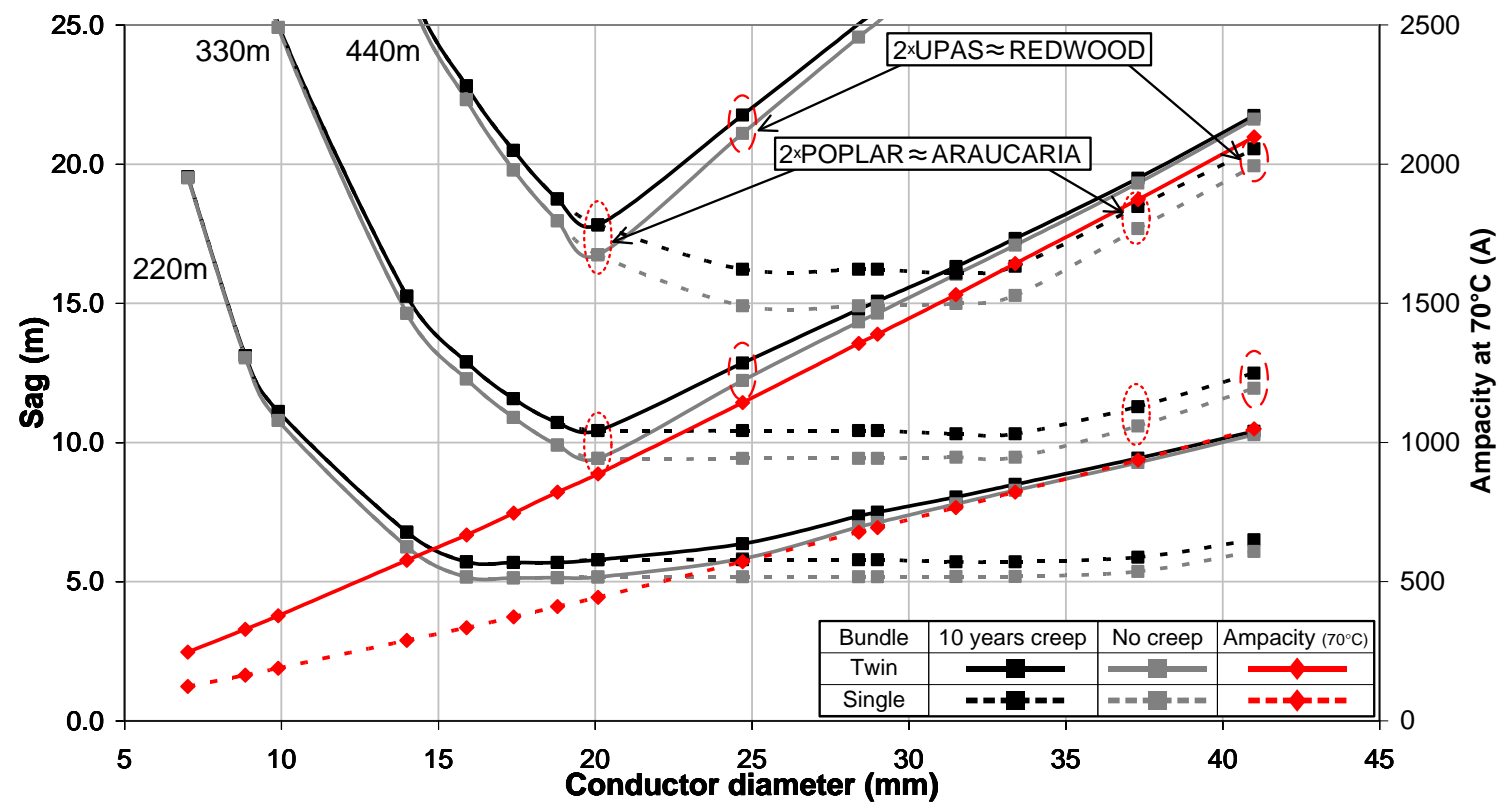

Figure 4 

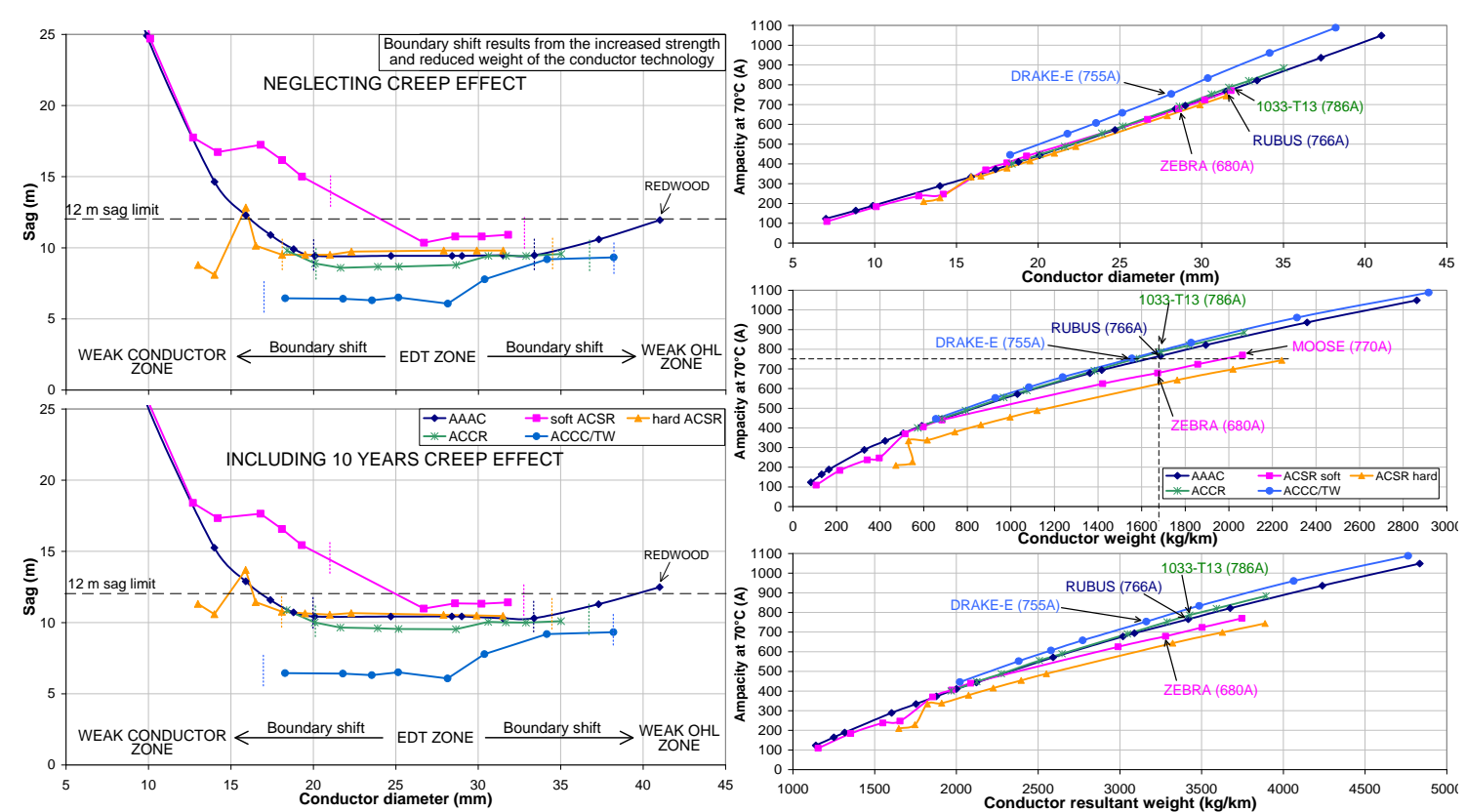

Figure 5

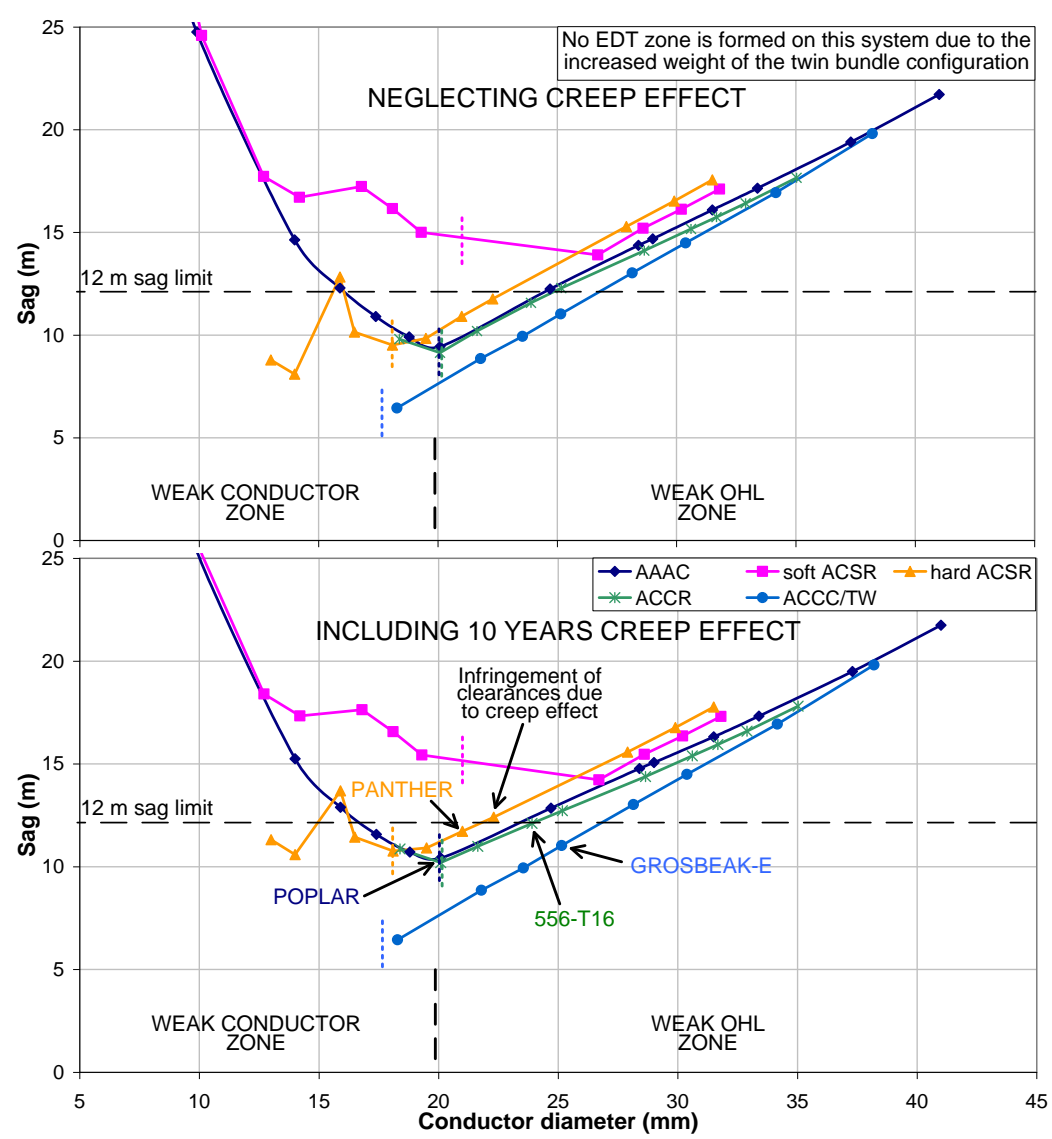

Figure 6 

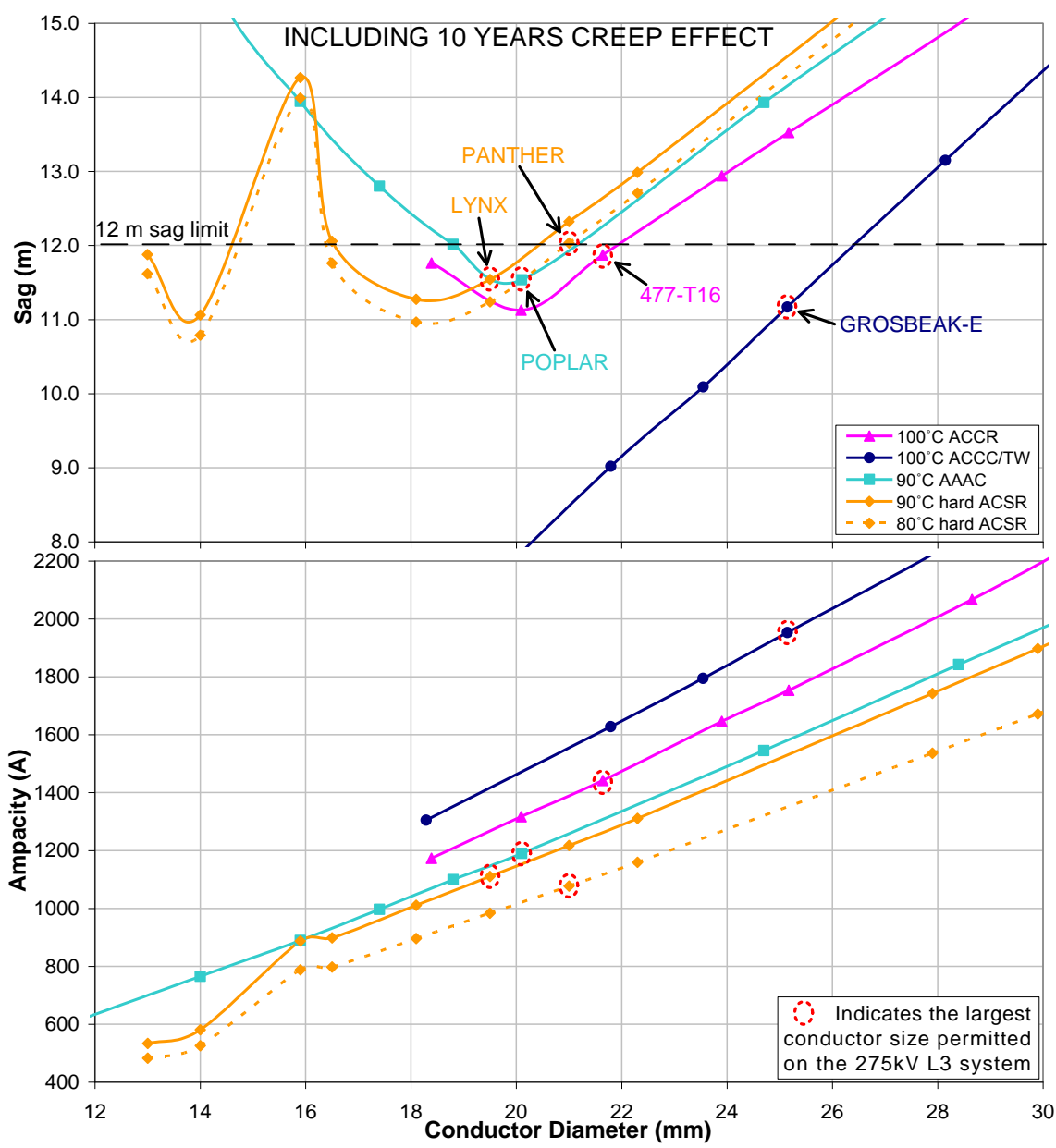

Figure 7

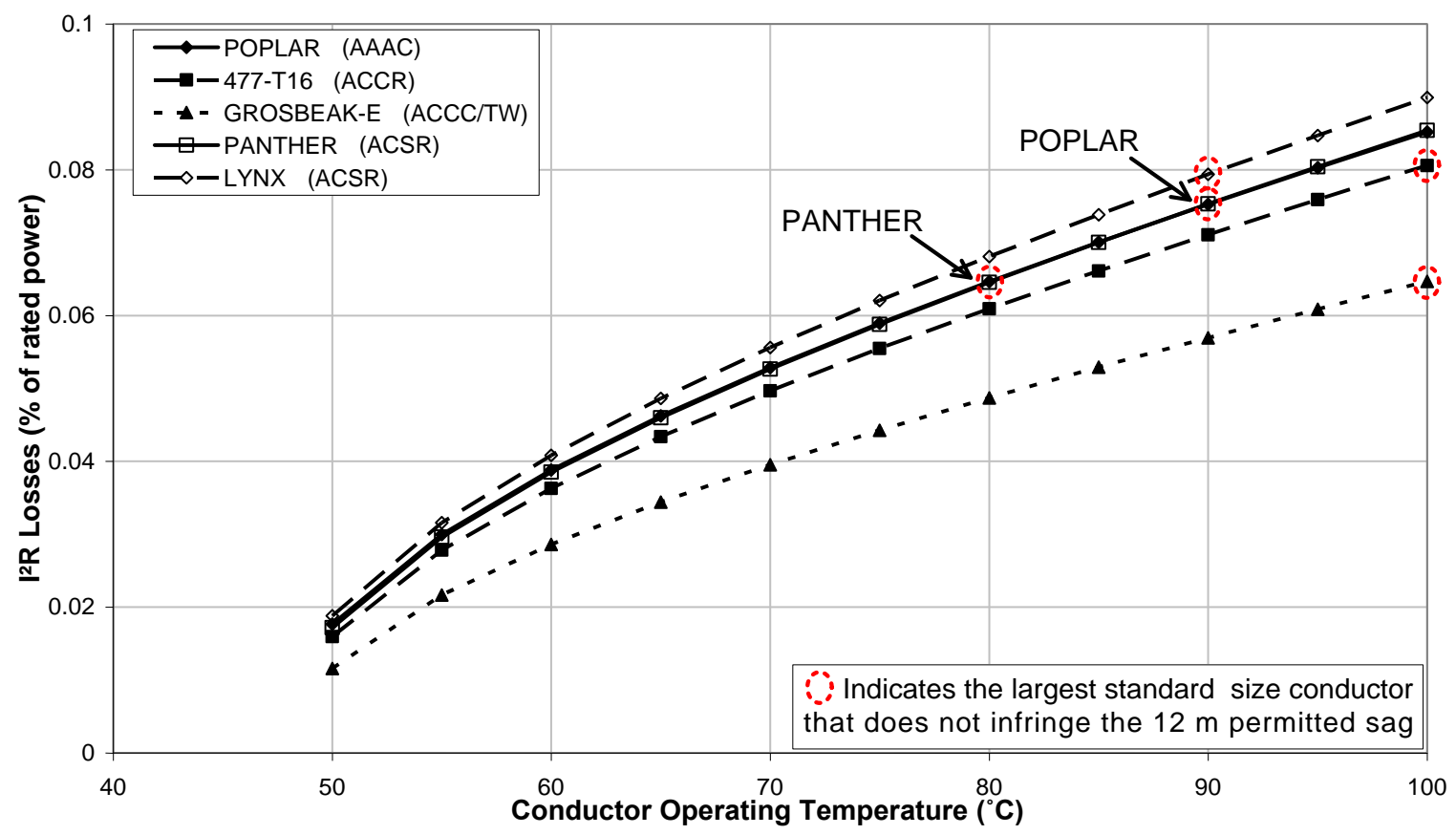

Figure 8 